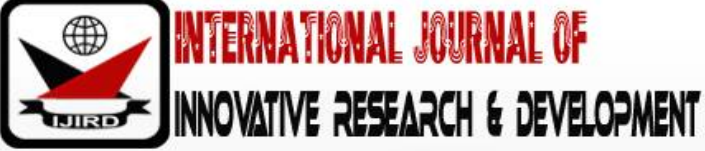

ISSN 2278 - 0211 (Online)

\section{Biodiesel Production from Neem (Azadirachtaindica) Seed Oil}

\author{
Tahiru Abdul - Wahab \\ Environmentalist, Department of Environmental Science, University of Cape Coast, \\ University of Cape Coast, Ghana \\ Dr. Mohammed A. Takase \\ Environmentalist, Department of Environmental Science, University of Cape Coast, \\ University of Cape Coast, Ghana
}

\begin{abstract}
:
Biodiesel was produced from non-edible neem seeds. Due to its high FFA content, a two step acid-basetransesterification approach was applied using $\mathrm{H}_{2} \mathrm{SO}_{4}-\mathrm{NaOH}$. In the first approach (esterification), $\mathrm{H}_{2} \mathrm{SO}_{4}$ was applied to reduce acid level to $<1 \mathrm{mgKOH} / \mathrm{g}$ while the followup step involved direct conversion to fatty acid methyl ester using $1 \% \mathrm{NaOH}$ as catalyst. The results revealed optimum conditions of biodiesel at $1 \% \mathrm{NaOH}$ catalyst amount, $6{ }^{\circ} \mathrm{C}$ reaction temperature, 1:6 oil to methanol molar ratio and 70 min reaction time for the two step acid - basetransesterification method. These optimum parameters produced a maximum biodiesel yield of $92.0 \%$.

The fuel properties of the biodiesel produced compared favorably with recommendations by the American Standard Testing Method (ASTM D6751), European Standard and Ghana Standard Authority
\end{abstract}

Keywords: Biodiesel, Transesterification, esterification, homogeneous, heterogeneous, Neem, characterization, methanol, free fatty acid

\section{Introduction}

The depletion of fossil fuel, the resulting high price and it's adverse effects on the environment has encouraged successive governments and researchers in recent times to consider alternative renewable sources of fuels. Renewable and clean energy fuel can be produced from different bio based raw material as a substitute for petro based products. Production of biofuels from renewable feed stocks can improve energy security and reduce greenhouse emissions. In the wake of this phenomenon, demand for energy and its security by various countries has shot up globally (Radha \& Manikandan, 2011).

The term biodiesel refers to a clean burning alternative fuel, produced from domestic, renewable resources like vegetable oils, recycled cooking oils, or animal fats (Sivaramakrishnan\&Ravikumar, 2012). Because plants produce oils from sunlight and air, and can do so year after year on cropland; these oils are best described as renewable. Animal fats are produced when the animal consumes plant oils and other fats, and they too are renewable. Biodiesel contains no petroleum, but it can be blended at any level with petroleum diesel to create a biodiesel blend. It can be used in compression-ignition (CI-diesel) engines with little or no modifications. Short chain alcohols such as methanol, ethanol, and butanol are very often used in the production of biodiesel. The selection of an alcohol is premised on several factors including cost effectiveness and performance considerations. Ethanol and methanol are much preferred among the most used alcohols (Saraf \& Thomas, 2007). Whereas methanol is less costly with desirable physical and chemical attributes, ethanol is environmentally friendlier since it is sourced from renewable agricultural materials thus, making the transesterification process a total independence from petroleum-based alcohol (Saraf\&Thomas,2007) . The high cost of edible plant and vegetable oils as raw materials used for biodiesel production is the major setback which greatly retards its widespread application. Thus, biodiesel production has not yet been commercialized all over the world (Yan et al., 2010). One way of reducing the cost of biodiesel is to employ low quality feedstocks such as waste or used vegetable oils, non-edible oils and soap stock (by-product of vegetable oil refinery), which are cheaply available and can be regarded as attractive feedstocks for biodiesel production (Canakci \& Sanli, 2008).

Transesterification is the most common method for biodiesel production due to its simplicity, thus this method has been widely used to convert vegetable oil into biodiesel (Helwani et al., 2009). The transesterification process or methanolysis (alcoholysis), which refers to a catalyzed chemical reaction involving vegetable oil and $\mathrm{MeOH}$ to yield fatty acid methyl ester as the main product and glycerol as a by-product (Huber, O'Connor \& Corma, 2007), is shown in the equation below;

$\mathrm{TG}+3 \mathrm{MeOH} \stackrel{\text { CATALYST }}{\longleftrightarrow}$ GLYCEROL $+3 \mathrm{Me} \ldots \ldots \ldots \ldots \ldots . . \mathrm{eq}(1)$

Where TG, MeOH and ME denote triglyceride, methanol and methyl esters respectively. 
Methods such as; conventional, non-catalytic supercritical, microwave and ultrasound are also employed in biodiesel production (Teixeira et al.,2009; Azcan \& Danisma, 2008; Georgogianni, Kontominas, Pomonis, Avlonitis, \& Gergis, 2008) Among these methods, conventional stirring and ultrasonication are much preferred and widely studied with different feedstocks (Marchetti, 2007). However, conventional stirring is preferred in most cases because of its convenience, easy and simple nature of application.

According to Meher,Vidya, Sagar,andNaik, (2006)the majority of feedstock currently used are obtained from edible agriculture resources. Biodiesels from edible oils are currently affected by concerns bordering on cost because of the competition that exists between food and fuel from edible oils; a major factor fuelling the change in narrative for more non-edible low-cost alternative feedstocks. According to Radha and Manikandan. (2011) neem is a viable alternative to Jatropha and Castor, Neem seed can be a potential and promising feedstock for biodiesel production with extra environmental and socioeconomic importance. Neem tree is available in virtually all the ten (10) regions of Ghana. Currently the tree doesn't have any significant use except for shade and in rare cases for medicinal purposes (Workneh, 2011).

Neem (Azadirachtaindica) is a fast growing tree, easily cultivable, drought resistant, grows under poor soil conditions, has less annual rain fall requirement (not more than $200 \mathrm{~mm}$ ), and other agricultural activities such as crop growing or livestock rearing can be carried out along with a neem tree plantation. In addition, the by-product like the seed cake can be used for soil conditioning; leaf extract can be used for waste water treatment and for production of pesticide and insecticide. The aforementioned importance and other significant multi benefits make the tree attractive for biodiesel production.

Firstly, atwo stepacid -basetransesterification process is adopted to convert the high free fatty acid (FFA) oils to its mono-esters. Step one involves, acid catalyzed esterification to reduce the free fatty acid(FFA) content of the oil to less than $2 \%$,followed almost immediately with a second step, entailing alkaline catalyzedtransesterification process to converts the products obtained in step one to its mono-esters and glycerol.

The objectives of this work were to evaluateand optimize the transesterification of neem seed oil using a two stepacid-basetransesterification method using $\mathrm{H}_{2} \mathrm{SO}_{4}-\mathrm{NaOH}$ and to compare yield/ quality with international standards. The obtained results can be used to predict a conversion yield of neem oil transesterification going forward.

\section{Materials and Method}

\subsection{Materials and reagents}

Chemicals including methanol, $\mathrm{NaOH}, \mathrm{H}_{2} \mathrm{SO}_{4}, \mathrm{KOH}$, petroleum ether $\left(60-90{ }^{\circ} \mathrm{C}\right)$, hydrochloric acid (HCL) and tetradecane (internal standard for GC) were obtained from the school of biological sciences (UCC) and were all of analytical reagent (AR) grade.

\subsection{Apparatus}

The apparatus used in this study include, Oven, heating mantle, crucible,thermometer, desiccators, centrifuge, mortar and pestle, mill, rotary evaporator, $250 \mathrm{ml}$ two neck reaction flask, separating funnel, hot plate, condenser, magnetic stirrer, water bath, micropipette, Gas chromatograph (GC) (Agilent Technology Inc. USA).

\subsection{Procedures}

\subsubsection{Acid Pre-Treatment (Acid Catalyzed Esterification)}

The extracted crudeneem oil was first weighed, heated at $60^{\circ} \mathrm{C}$ for about 10 min and mixed with $45.0 \mathrm{ml}$ of methanol ( $4.5: 1$ methanol to oil ratio). $0.5 \% \mathrm{w} / \mathrm{w}$ of concentrated $\mathrm{H}_{2} \mathrm{SO}_{4}$ was added to the mixture. The obtained resulting mixture was then stirred with the aid of a magnetic stirrer on a plate for $50 \mathrm{~min}$ at $60^{\circ} \mathrm{C}$, after which it was allowed to settle for 2 hours. The acid treatedoil is separated from the methanol - water mixture with the aid of a separating funnel.

\subsubsection{Base Catalyzedtransesterification}

These laboratory scale experiments were carried out batch wise ina $250 \mathrm{ml}$ conical flask containing $25 \mathrm{~g}$ of pretreatedneem oil. These were done with a magnetic stirrer on a plate at a temperature of $60^{\circ} \mathrm{C}$, varying oil to alcohol ratio from 1:4, 1:6,1:8to1:10. The acid treated oil was poured into the reactionflask and heated. A solution of $\mathrm{NaOH}$ in methanol (1\%) was dissolved at room temperature and the pre-treated oil was added. The reaction time spanned through various periods of $50,60,70$ and $80 \mathrm{~min}$. The reaction condition of $60^{\circ} \mathrm{C}$ and $1 \% \mathrm{NaOH}$ catalyst was maintained as reported previously (Aransiola et al., 2010; Muthuet al., 2010).The resulting mixture was poured into a separating funnel and allowed to settle under gravity for 24 hours. The rather heavier glycerol settled in the lower layer and was tapped off before the biodiesellayer which was subsequently washed with warm water three times and dried over anhydrous calcium chloride. The viscosity value recorded for the biodiesel produced was adopted as aproxy estimation of the extent of reaction with reference to ASTM standard which served as an indicator of completeness of the transesterification reaction. The aforementioned approach has been used in the literatures (Aransiolaet al., 2010). The procedure employed in this study was repeated varying catalyst amount, temperature and reaction time constant and mole ratio in the quest to yield optimum reaction conditions. The biodiesel produced was analyzed for various parameters including: density, acid value, ash content, pour point, flash point, cloud point, water content, colour, density, and kinematic viscosity at $40^{\circ} \mathrm{C}$. 


\subsection{Analysis of FAME Yield}

The analysis for the composition of the oil sample was carried out with the aid of a 7890B GC-MS (Agilent Technology Inc. USA) according to ASTM D6584.The GC-MS was equipped with a thermal conductivity detector (TCD) and a high-polarity general purpose column recommended for Free Fatty Acid and Phenols (15\% FFAP, Chromosorb W, A/ W 80/ 100, Length of $2 \mathrm{~m}$ ). Helium at high purity $99.9999 \%$ was used as the carrier gas. Column operation temperature range of $50^{\circ} \mathrm{C}-250^{\circ} \mathrm{C}$ and sample inlet temperature of $200^{\circ} \mathrm{C}$ were used. The temperature of the oven was initially held at $60^{\circ} \mathrm{C}$ for $5 \mathrm{~min}$ and then increased to $220^{\circ} \mathrm{C}$ at $10^{\circ} \mathrm{C} / \mathrm{min}$ for $10 \mathrm{~min}$. Sample inlet pressure (Carrier gas $20 \mathrm{~mL} / \mathrm{min}$ ) and total pressure with makeup (Carrier gas and makeup $21 \mathrm{~mL} / \mathrm{min}$ ) were used. Temperature of the detector was $250^{\circ} \mathrm{C}$.

The neem oil was analyzed for characterization. Standard ASTM D6751 methods were being used to determine, at kinematic viscosity $40^{\circ} \mathrm{C}$ (ASTM D445-06), densityat $15^{\circ} \mathrm{C}$ (ASTM D4052-96) acid value (ASTM D664-06), saponification value (GB/ T5534-08), FFA (ASTM D5555-95)and water content (ASTM D2709-96).

The yields of the biodiesel samples were determined from the content of the esters using the equation below;

Me yield $(\%)=\frac{\% \text { FAME area from GCMS } \times \text { weight of product }}{\text { weight ofoil sample }} \times 100 \% \quad$ (Omar\&Amin,2011)

All data points were presented as means of triplicate for both experimental and GC analysis.

\section{Results}

\subsection{Esterification of Neem Oil Using Sulphuric Acid}

Free fatty acid and moisture content are key parameters for determining the viability of the vegetable oil transesterification process. Feed stocks with high free fatty acid ( $>1 \%)$ are not easily converted by base catalyzed transesterification processes because of the occurrence of concurrent soap formation, which has a potential of reducing catalyst efficiency, increase viscosity and glycerol separation difficulty. To avoid the above problems, obtained free fatty acids were pre-treated via sulphuric acid treatment into esters with methanol as shown in the equation below:

$\mathrm{RCOOH}+\mathrm{CH}_{3} \mathrm{OH} \mathrm{H}_{2} \mathrm{SO}_{4} \mathrm{RCOOCH}_{3}+\mathrm{H}_{2} \mathrm{O}$.

\subsection{Methanol: Oil Molar Ratio}

As can be seen in figure 1, holding catalyst amount at $0.5 \mathrm{wt} . \%$, reaction temperature at $60{ }^{\circ} \mathrm{C}$ and reaction time at $40 \mathrm{~min}$, the increase in methanol-to-oil molar ratio proportions from 3.5:1 to 4.5:1, correspondingly increased yield from $80 \%$ to $90.2 \%$. The last two of the series being, 5.0:1 and 5.5:1 produced only a slight decline when methanol: oil molar ratio further increased.

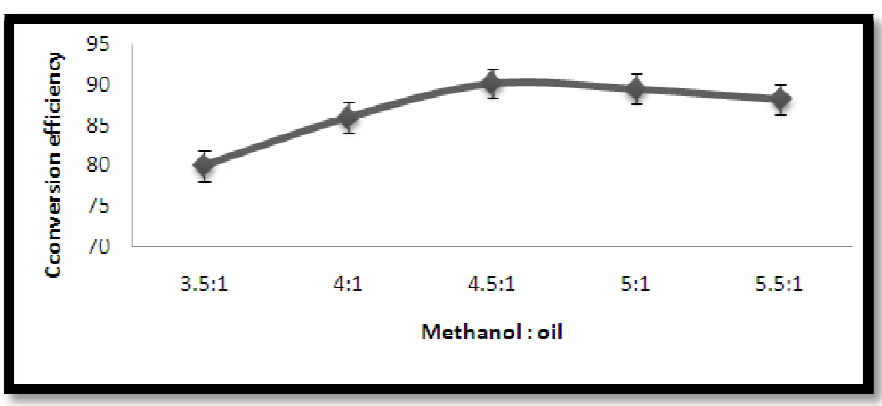

Figure 1: Effect of Methanol on Conversion Efficiency

\subsection{Catalyst Amount}

Amount of acid catalyst variation affects the conversion efficiency. Sulphuric acid proportions when varied from $0.25,0.5,0.75$ to $1 \% \mathrm{v} / \mathrm{vH}_{2} \mathrm{SO}_{4}$ (holding Molar ratio at 4.5:1, reaction temperature at $60{ }^{\circ} \mathrm{C}$ and reaction time at $40 \mathrm{~min}$ ). Maximum conversion efficiency is observed at $0.5 \% \mathrm{v} / \mathrm{vH}_{2} \mathrm{SO}_{4}(90.2 \%)$ as can be seen from Figure 2, a decline is observed as the catalyst amount increased.

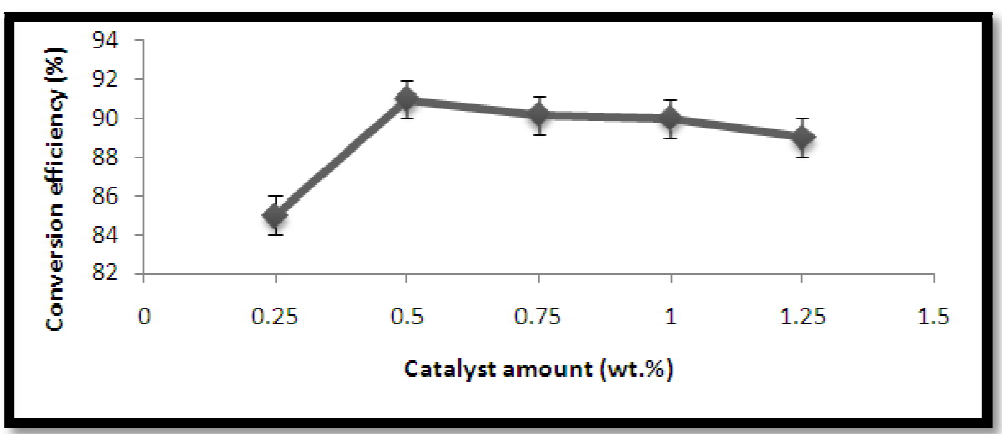

Figure 2: Effect of Acid Catalyst Amount on Conversion Efficiency 


\subsection{Reaction Temperature}

Maintaining methanol: oil molar ratio at 4.5:1, catalyst amount at $0.5 \% \mathrm{v} / \mathrm{v} \cdot \mathrm{H}_{2} \mathrm{SO}_{4}$ and reaction time at $40 \mathrm{~min}$, the increase in temperature from $40{ }^{\circ} \mathrm{C}$ to $60^{\circ} \mathrm{C}$ resulted in an increase in conversion efficiency from $80 \%$ to $90 \%$. Optimum temperature was achieved at $60^{\circ} \mathrm{C}$ as can be seen from Figure 3.

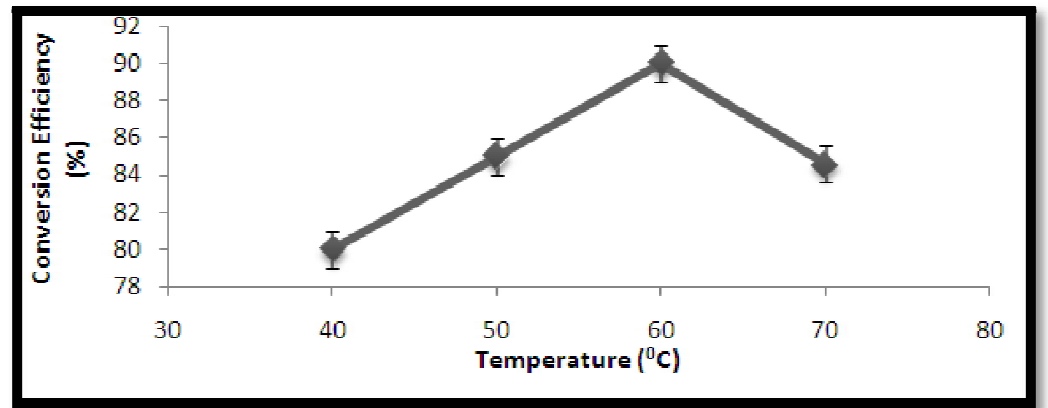

Figure 3: Effect of Temperature on Conversion Efficiency

\subsection{Reaction Time}

As can be seen from Figure 4, the maximum conversion efficiency (90.1\%) was achieved in 50min. The excess reaction time (after 50min) resulted in slight reduction in conversion efficiency possibly due to the reversibility of the reaction

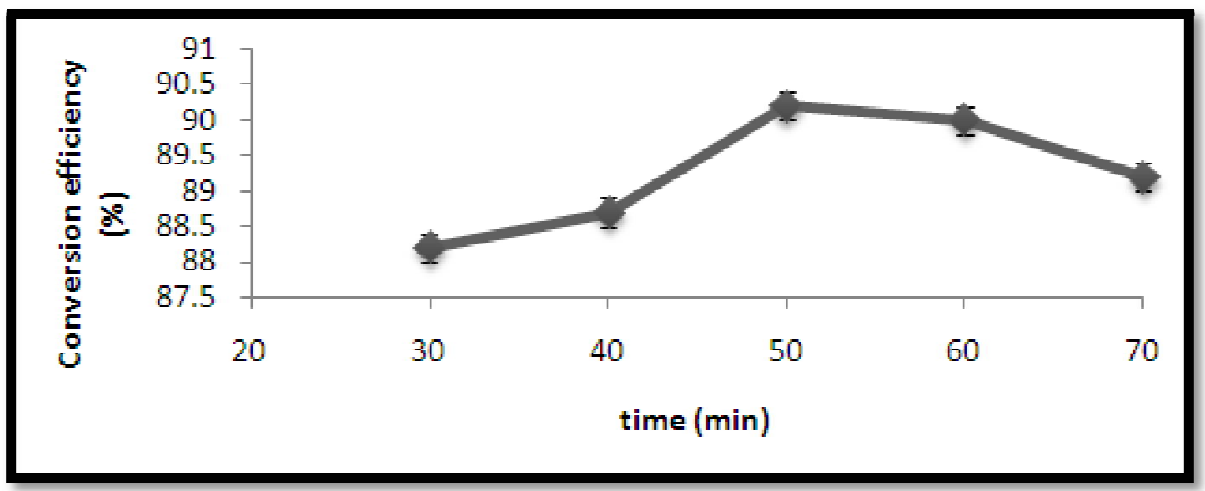

Figure 4: Effect of Time on Conversion Efficiency

In this experiment, $4.5: 1$ methanol to oil molar ratio, $50 \mathrm{~min}$ reaction time, $60^{\circ} \mathrm{C}$ reaction temperature and $0.5 \mathrm{wt} . \%$ catalyst amount were finally selected as the attained optimum reaction conditions for the esterification of neem oil.

\subsection{Alkali transesterification using $\mathrm{NaOH}$}

\subsubsection{Methanol: Oil Molar Ratio}

Effect of methanol on the biodiesel yield was studied at constant temperature, time and catalyst to oil weight ratio that is, $60^{\circ} \mathrm{C}, 70 \mathrm{~min}$ and $1 \%$, respectively. As can be observed from Figure 5, the increase of methanol: oil molar ratio from 1:4 to $1: 6$, increases biodiesel yield from $87.43 \%$ to $90.33 \%$. However, further increase in methanol: oil molar ratio reduced the yield.

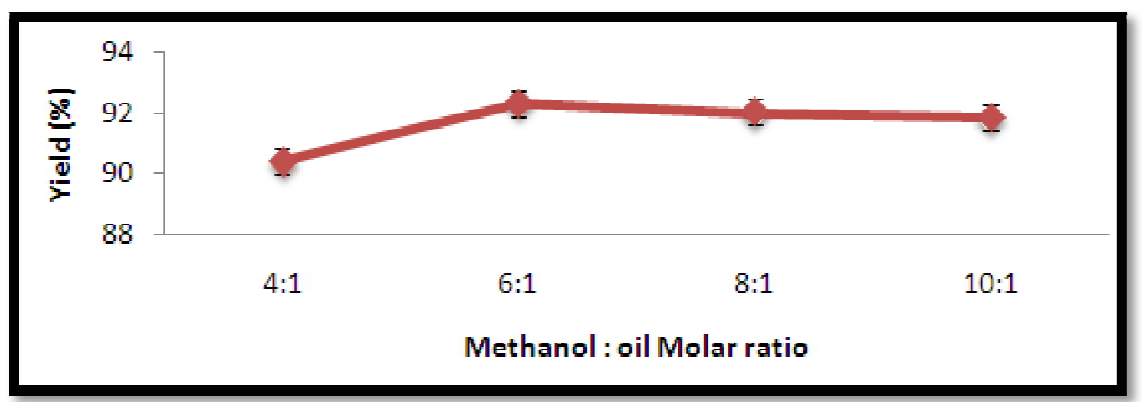

Figure 5: Effect of Methanol on Yield

\subsection{Catalyst Amount}

Figure 6 shows that, the increase of catalyst amount has a significant positive effect on FAME yield. It can be observed that maximum yield (92.3\%) was achieved when the catalyst dosewas increased from $0.5 \mathrm{wt} . \%$ to $1 \mathrm{wt} . \%$, a further increase resulted in yield decline. 


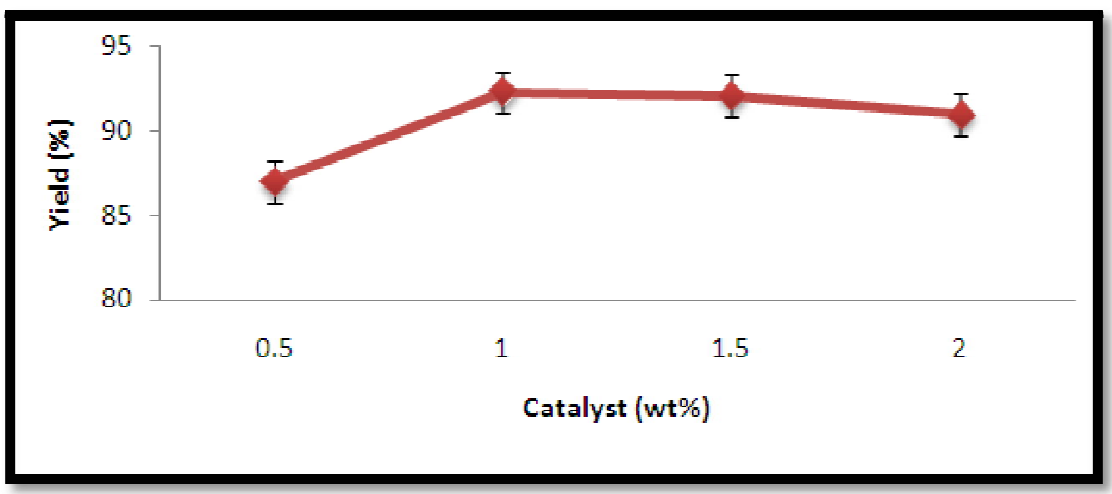

Figure 6: Effect of Catalyst on Yield

\subsection{Reaction Temperature}

The effect of reaction temperature variation on yield is shown in figure 7. Temperature was varied in four different levels that is; $50,60,70$ and $80^{\circ} \mathrm{C}$. Amongst these, $70^{\circ} \mathrm{C}$ reaction temperature gave the maximum methyl ester yield of $92.6 \%$.

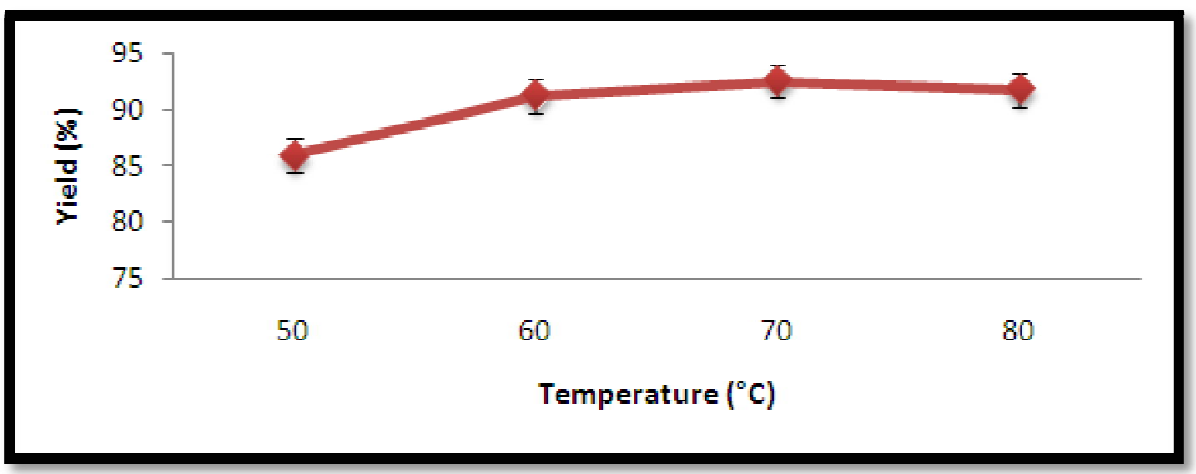

Figure 7: Effect of Reaction Temperature on Yield

\subsection{Reaction Time}

The effect of reaction time variation on the conversion efficiency is shown in Figure 8. It can be seen that, increase in reaction time from $50 \mathrm{~min}$ to $60 \mathrm{~min}$ increased FAME yield from $87.0 \%$ to $92.5 \%$. A further increase in reaction time led to a slight decline in yield.

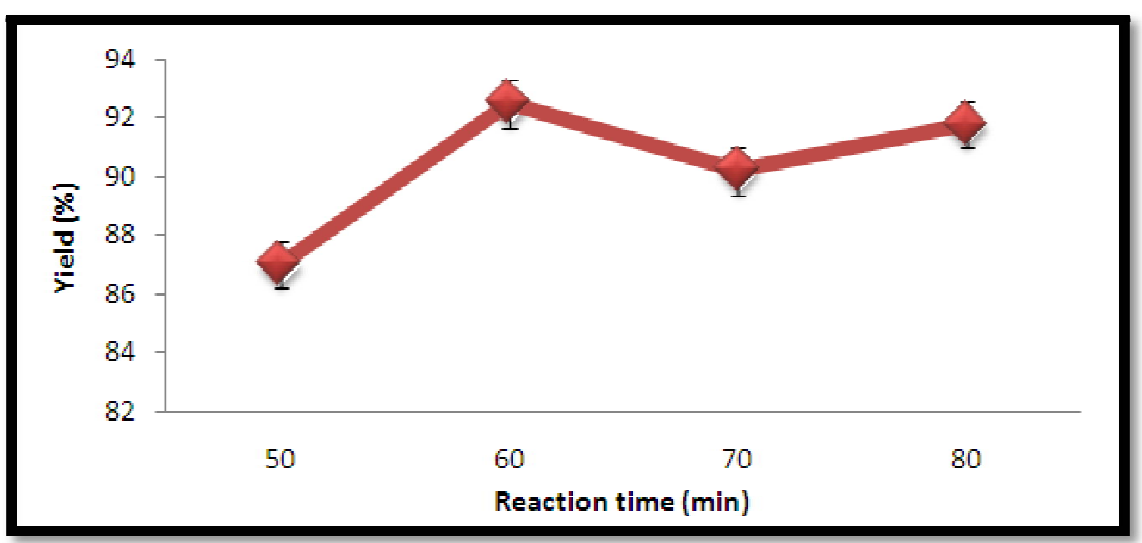

Figure 8: Effect of Reaction Time on Yield

From the experiment, it was determined that the optimum parameters for transesterification of Neem oil using $\mathrm{NaOH}$ after the pre acid treatment with $\mathrm{H}_{2} \mathrm{SO}_{4}$ are 6:1 methanol:oil molar ratio, $1 \mathrm{wt} \%$ catalyst loading, $60{ }^{\circ} \mathrm{C}$ reaction temperature, and $70 \mathrm{~min}$ reaction time. These optimum parameters for transesterification of neem oil produced the highest methyl ester yield of $92.0 \%$.

\subsection{Characterization of the Methyl Esters}

The chromatogram of methyl ester produced from $\mathrm{NaOH}$ catalyzed transesterification is presented in Figure 9. Analysis in this study was mainly carried out to confirm the conversion of oil to methyl ester. The methyl ester eluted at a retention time of 2.310 minutes was a little lower than that of the standard ( 2.460 minutes). The difference may be due to instrumental and/ or experimental error. 


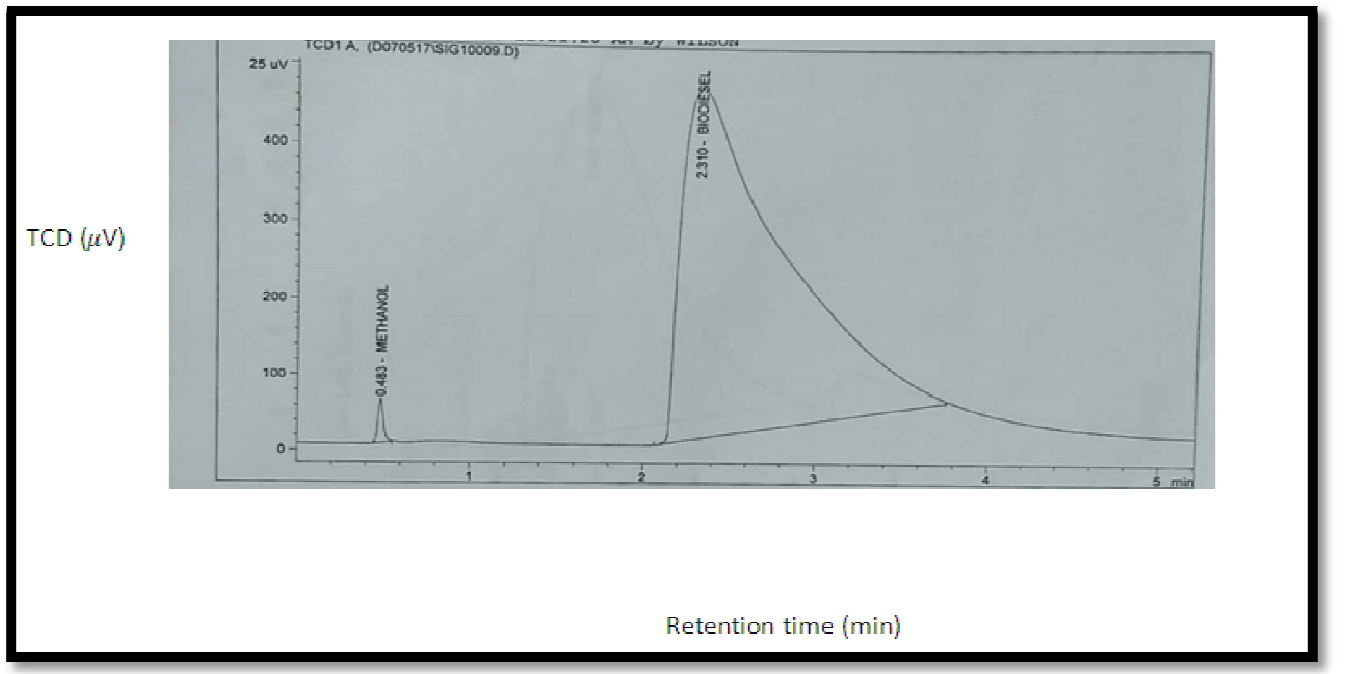

Figure 9: Chromatogram of the Methyl Ester

From table 1, all properties of the methyl ester obtained from $\mathrm{NaOH}$ catalyzed transesterification were within the standard limits, thus, making the biodiesel suitable for use.

\begin{tabular}{|c|c|c|c|c|c|}
\hline Property & Acid Treated Oil & Akali FAME & $\begin{array}{c}\text { ASTM } \\
\text { Standard } \\
\text { D6751 }\end{array}$ & $\begin{array}{c}\text { EN } \\
\text { Standard }\end{array}$ & $\begin{array}{c}\text { Ghana } \\
\text { Standard } \\
\text { Authority }\end{array}$ \\
\hline Density, kg/m3 & 910 & 890 & $870-900$ & $860-900$ & - \\
\hline $\begin{array}{c}\text { Kinematic } \\
\text { Viscosity(mm2/ s), 40 0C }\end{array}$ & 27.4 & 4.68 & $1.9-6.0$ & $3.5-5.0$ & $1.5-6.5$ \\
\hline Iodine Value (g/ 100g) & 70 & 52.62 & - & $\leq 120$ & - \\
\hline Acid value (mg KOH/g) & 0.7508 & 0.31 & $\leq 0.8$ & $\leq 0.5$ & $\leq 1.0$ \\
\hline Saponification value & 222.2 & 148.6 & - & - & - \\
\hline $\begin{array}{c}\text { (mgKOH/g) } \\
\text { Ash content (\%) }\end{array}$ & 0.00 & 0.01 & - & - & $\leq 0.1$ \\
\hline Cloud point (0C) & - & +3 & - & - & - \\
\hline Flash point (0C) & - & 180 & $\geq 120$ & $\geq 130$ & $66 \mathrm{~min}$ \\
\hline
\end{tabular}

Table 1: Properties of the Methyl Ester Compared to International Standards

\section{Discussions}

\subsection{Esterification of Neem Oil Using Sulphuric Acid}

Molar ratiois defined as the ratio of number of moles of alcohol to number of moles of vegetable oil. Theoretically, transesterification reaction requires 3 moles of alcohol for each mole of oil. However, practically a higher molar ratio is required to shift reaction equilibrium towards the products for more methyl esters yield. As can be seen in Figure 1, the highest conversion efficiency is achieved when methanol-to-oil molar ratioproportions increased from 3.5:1 to 4.5:1 (catalyst amount $0.5 \mathrm{wt} . \%$, reaction temperature $60^{\circ} \mathrm{C}$ and reaction time $40 \mathrm{~min}$ ), the last two of the series being, 5.0:1 and 5.5:1 produced only a slight decline. In economic sense $4.5: 1 \mathrm{M}$ is chosen as the optimum reaction condition. Beyond this ratio, the additional methanol did not contribute positively to the production yield.

Effect of acidcatalystamount variation affects the conversion efficiency. Maximum conversion efficiency is observed when the catalyst amount increased from 0.25 to $0.5 \% \mathrm{v} / \mathrm{vH}_{2} \mathrm{SO}_{4}$.The product turns black beyond $0.5 \%$ $\mathrm{v} / \mathrm{vH}_{2} \mathrm{SO}_{4}$. Catalyst variation is shown in Figure 2.

Maintainingmethanol to oil molar ratio at 4.5:1, catalyst amount at $0.5 \% \mathrm{v} / \mathrm{vH}_{2} \mathrm{SO}_{4}$ and reaction time at $40 \mathrm{~min}$, the increase in temperature from $40^{\circ} \mathrm{C}$ to $60^{\circ} \mathrm{C}$ resulted in an increase in conversion efficiency. Optimum temperature is achieved at $60^{\circ} \mathrm{C}$.At higher reaction temperature methanol is lost because melting point of methanolis $65^{\circ} \mathrm{C}$. Above $60^{\circ} \mathrm{C}$ product colour became black. Effect of temperature variation is shown in figure 3.

The reaction time was varied from 30 to $70 \mathrm{~min}$. As can be observed in Figure 4, the reaction was slow in the initial stages possibly due to inadequate stirring time to enhance proper mixing and dispersion of methanol and catalyst onto the oil. The maximum conversion efficiency (90.1\%) was however, achieved in 50min. The excess reaction time (after 50min) resulted in a slight reduction in the conversion efficiency due to reversibility of the reaction.

The observation in this study compares favourably with that of Sathya and Manivannan.(2013) who reported a catalyst amount of $0.5 \% \mathrm{v} / \mathrm{v} \mathrm{H}_{2} \mathrm{SO}_{4}$, methanol : oil molar ratio $(0.45: 1 \mathrm{v} / \mathrm{v})$ at $50^{\circ} \mathrm{C}$ temperature and 45 min reaction time as optimum reaction conditions for the esterification of neem seed oil. In this experiment, 0.45:1 methanol to oil molar ratio, 
50 min reaction time, $60^{\circ} \mathrm{C}$ reaction temperature and $0.5 \mathrm{wt} . \%$ catalyst amount were finally selected as the finally attained optimum reaction conditions.

The oil's acid value reduced to less than $2 \mathrm{mgKOH} / \mathrm{g}$ and its color became lighter after acid treatment. This made it much more convenient for alkali transesterification (Ghadge \& Raheman, 2006; Veljkovic et al., 2006; Wang et al., 2011). The viscosity of the oil reduced after transesterification from 43.75 to $5.53 \mathrm{cSt}$ likewise the density from 0.9182 to 0.8762 $\mathrm{g} / \mathrm{ml}$, which is acceptable as per ASTMD664-01 recommendation for biodiesel.

\subsection{Alkali transesterification Using $\mathrm{NaOH}$}

Theoretically one mole of triglyceride requires three moles of methanol, but in practice higher amount is required to shift the reaction equilibrium forward and maximize theyield. Effect of methanol on the FAME yield was studied at constant temperature, time and catalyst to oil weight ratio i.e. $60^{\circ} \mathrm{C}, 70 \mathrm{~min}$ and $1 \%$, respectively. As can be observed in Figure 5,the increase in methanol to oil molar ratio from 1:4 to 1:6, increased FAME yield from 87.43\% to $90.33 \%$. However, further increase did not have a significant impact on the yield. Methanol to oil molar ratio of 1:10 results in 90.83\% FAME yield which is almost similar to methanol to oil molar ratio of 1:6. This is because, as the amount of methanol increases, it shifts the reaction equilibrium forward (i.e. sincetransesterification reaction is reversible) which consequently results in increase in rate of reaction. However, further increase in methanol leads to dilution of the catalyst. In addition, most probably at higher amount of methanol, reverse reaction which is acombination of glycerol and ester may have started to take place, these phenomena often leads to the formation of di and monoglyceride, which results in incomplete conversion.

The amount of catalyst is an important process variable in the production of biodiesel. In this experiment, catalyst to oil weight ratio was varied from $0.5 \%$ to $2.0 \%$. The reaction condition of $60^{\circ} \mathrm{C}$ temperature, $60 \mathrm{~min}$ reaction time and $6: 1$ methanol to oil molar ratio was maintained as reported previously (Aransiola et al., 2010; Muthu etal., 2010). Figure 6 shows that increasing the catalyst amount has a significant positive effect on FAME yield. It was observed that when the catalyst dose was low, incomplete transesterification occurred. However, as the amount increased, more triglycerides changed to ester. This is because, increasing the catalyst amount provides more active sites for the reaction of available triglyceride and methanol. In addition, a further increase in catalyst amount (beyond 1wt.\%), slightly lowered the yield from 1 wt.\% (92.3\%) to 2.wt.\% (91.0\%), a development attributable to soap formation.

Effect of temperature was studied by holding methanol to oil molar ratio, catalyst and time constant at 1:6, 1\% and 70min respectively. Figure 7 has shown that, increasing the temperature at higher catalyst loading (beyond 1.0\%) has a negative effect on the yield, however this effect was negligible at lower catalyst to oil weight ratio. This is because maximum yield was observed at a higher catalyst, methanol amount; any action disrupting this combination has negative effect on the FAME yield. The yield is increased with increase in reaction temperature.

The effect of temperature variation on yield is shown in figure 7 where, temperature was varied in four different levels i.e.50,60,70 and $80^{\circ} \mathrm{C}$.Amongst these variations, $60^{\circ} \mathrm{C}$ reaction temperature gave the maximum methyl ester yield $(92.6 \%)$. The slight decline observed beyond $60^{\circ} \mathrm{C}$ is possibly as a result of loss/escape of methanol. The conversion rate increased within crease in reaction time. In this experiment, reaction time varied from 50-80min.

The effect of reaction time variation on the conversion efficiency is shown in Figure 8. Increase in reaction time from 50min to $70 \mathrm{~min}$ increased FAME yield from $87.0 \%$ to $92.5 \%$. A further increase in reaction time caused a slight decline in yield possibly due to reversible reaction. 1:6 methanol to oil molar ratio, $70 \mathrm{~min}$ reaction time, $60^{\circ} \mathrm{C}$ reaction temperature and $1 \mathrm{wt} . \%$ catalyst amount were finally selected as the attained optimum reaction conditions.

The observation in this study compare favorably with Aransiola et al.(2010) who reported a catalyst amount of $1.25 \mathrm{wt} . \% \mathrm{NaOH}$, methanol : oil molar ratio(6:1), at $60^{\circ} \mathrm{C}$ temperature and 90 min reaction time as optimum reaction conditions for the transesterification of neem seed oil. In this experiment, 6:1 methanol to oil molar ratio, 70min reaction time, $60^{\circ} \mathrm{C}$ reaction temperature and $1 \mathrm{wt} . \%$ catalyst amount were finally selected as the optimum reaction conditions.

As can be seen in the FAME chromatogram presented in Figure 9, the biodiesel eluted at a retention time of 2.310 minutes which was lower than that of the standard (2.460 minutes). The slight difference is possibly as a result of instrumental and/ or experimental error.

As can also be seen in Table 1, the high initial neem oil figures of kinetic viscosity, saponification and acid value (43.74cSt, $199.86 \mathrm{Kg} / \mathrm{m}^{3}$ and $31.13 \mathrm{Kg} / \mathrm{m}^{3}$ respectively) reduced to kinetic viscosity $4.68 \mathrm{cSt}$, saponification $189.4 \mathrm{Kg} / \mathrm{m}^{3}$ and acid value $0.31 \mathrm{Kg} / \mathrm{m}^{3}$ after alkali transesterification using $\mathrm{NaOH}$. The values obtained were within the American Standard Test Method (ASTM D6751), European Standard and Ghana Standard Authority acceptable limits. The other parameters were also within the standard limits thus, making the biodiesel suitable for usage.

\section{Conclusion}

The following conclusions were made on the basis of the results obtained from this present study:

- The optimum reaction conditions for the acid - base transesterification reaction used in producing biodiesel from the neem oil are 1:6 methanol to oil ratio, $1 \mathrm{wt} . \%(\mathrm{NaOH})$ catalyst amount, $60^{\circ} \mathrm{C}$ reaction temperature and $70 \mathrm{~min}$ reaction time.

- The FAME yield obtained at optimum reaction conditions is $92 \%$ for two step acid base transesterification reaction of neem oil. 


\section{References}

i. Aransiola,E.F.,Daramola,M.,Ojumu, V. T.,Aremu, M.O., Stephen. k.,Layokun,S.K.,\& Solomon,B.O.(2010). Nigerian Jatropha Curcas Oil Seeds: Prospect for Biodiesel Production in Nigeria. International Journal ofBiological and Chemical Sciences, 2, 391- 399,

ii. ASTM. (2007). StandardSpecification for Biodiesel Fuel Blend Stock (B100) for Middle Distillate Fuels. Standard D 6751-07b. American Society for Testing andMaterials, West Conshohocken, PA (USA).

iii. ASTM. (2008). Standard specification for biodiesel fuel (B100) blend stock for distillate fuels, Method D6751-08. In: Annual Book of ASTM Standards, ASTM International: West Conshohocken, USA.

iv. Çanakçı, M., \& Șanali, A. (2008). Biodiesel production from various feedstocks and their effects on the fuel properties. J Ind Microbiol Biotechnol, 35, 431- 441.

v. Helwani Z., Othman M.R., Aziz N., Fernando, W,J,N., \& Kim, J. (2009) Technologies for production of biodiesel focusing on green catalytic techniques. Fuel Process. Technol, 90, 1502-1514.

vi. Huber, G.W., O'Connor, P.,\& Corma, A. (2007). Processing biomass in conventional oil refineries: production of high quality diesel by hydrotreating vegetable oils in heavy vacuum oil mixtures. Applied Catalysis A: General,329, 120-9.

vii. Ghadge, S.V.,\& Raheman, H. (2006). Process optimization for biodieselproduction from mahua (Madhuca indica) oil using response surfacemethodology. Bioresour. Technol, 97(3), 379-384.

viii. Georgogianni,K. G., Kontominas,M. G., Pomonis,P. J.,Avlonitis,D.,\& Gergis,V. (2008). Alkaline conventional and in situtransesterifcation of cottonseed oil for the production of biodiesel, Energy and Fuels, 22, 2110-2115.

ix. Marchetti, J., Miguel, V.,\& Errazu, A. (2007). Heterogeneous esterification of oil with high amount of free fatty acids. Fuel, 86, 906-10.

x. Meher, L.C., Vidya, Sagar. D.,\& Naik, S.N. (2006). Technical aspects of biodiesel production by transesterificationa review. Renewable and Sustainable Energy Reviews,10, 248-68.

xi. $\quad$ Muthu, H., Sathyaselvabala, V., Varathachary, T., Kirupha, S. D.,Nandagopal, J.,\& Subramanian, S.(2010).Synthesis of biodiesel fromNeem oil using sulfated zirconia via tranesterification. Braz.J. Chem.Eng, 27(4), 601-608.

xii. Omar, W.N.N.,\& Amin, N.S.(2011). Biodiesel production from waste cooking oil over alkaline modified zirconia catalyst. Fuel Processing Technology, 92, 2397-405.

xiii. Pereira, T., Portilho, C.M., Henriques, D., \& Zotin, B.(2014). Neem oil and neem oil components affect the effcacy of commercial neem insecticides. Journal of Agriculture and Food Chemistry, 43(2), 507-512.

xiv. Radha, K.V.,\& Manikandan, G.(2011). Novel production of biofuels from Neem oil. Bioenergy technology, world renewable energy congress,471 - 478.

xv. Sathya, T., \& Manivannan, A.(2013).Biodiesel production from neem oil using two steptransesterification.International Journal of Engineering Research and Applications, 3,488-492

xvi. Sivaramakrishnan, K. \&Ravikumar, P. (2012).Determination of cetane number of biodiesel and its influence on physical properties.ARPN Journal of Engineering and Applied Sciences; 7(2) ISSN 1819-6608.

xvii. Saraf, S.,\& Thomas, B.(2007). Influence of Feedstock and Process Chemistry on Biodiesel Quality. Process Safety and Environmental Protection,85, 3604.

xviii. Teixeira, L.S., Assis, J.C., Mendonça, D.R., Santos, I.T., Guimarães, P.R.,\& Pontes, L.A.(2009). Comparison between conventional and ultrasonic preparation of beef tallow biodiesel.Fuel Processing Technology, 90, 1164-6.

xix. Veljkovic,V., Lakicevic,S., Stamenkovic,O., Todorovic,Z.,\& Lazic,M. (2006).Biodiesel production from tobacco (Nicotiana tabacum L.) seed oilwith a high content of free fatty acids. Fuel, 85(17-18), 2671-2675.

xx. Wang, R., Hanna, M.A., Zhou, W.W., Bhadury, P.S., Chen,.Q., Song, B.A.,\& Yang,S. (2011). Production and selected fuel properties of biodiesel frompromising non-edible oils: Euphorbia lathyris L., Sapium sebiferum L and Jatropha curcas L. Bioresour. Technol, 102(2), 1194-1199.

xxi. Workneh, W. (2011), Extraction and characterization of essential oil from margosa, unpublished Thesis. School of chemical and bioengineering, Addis Ababa institute of technology. Ethiopia.

xxii. Yan, S., DiMaggio, C., Mohan, S., Kim, M., Salley, S.O., \& Simon, K. Y., (2010). Advancement in heterogeneous catalysis for Biodeseil synthesis. Springer Science+Business Media; 53:721-736. publishing: Golden, Colorado, 34, ISBN: 9781555916244. 